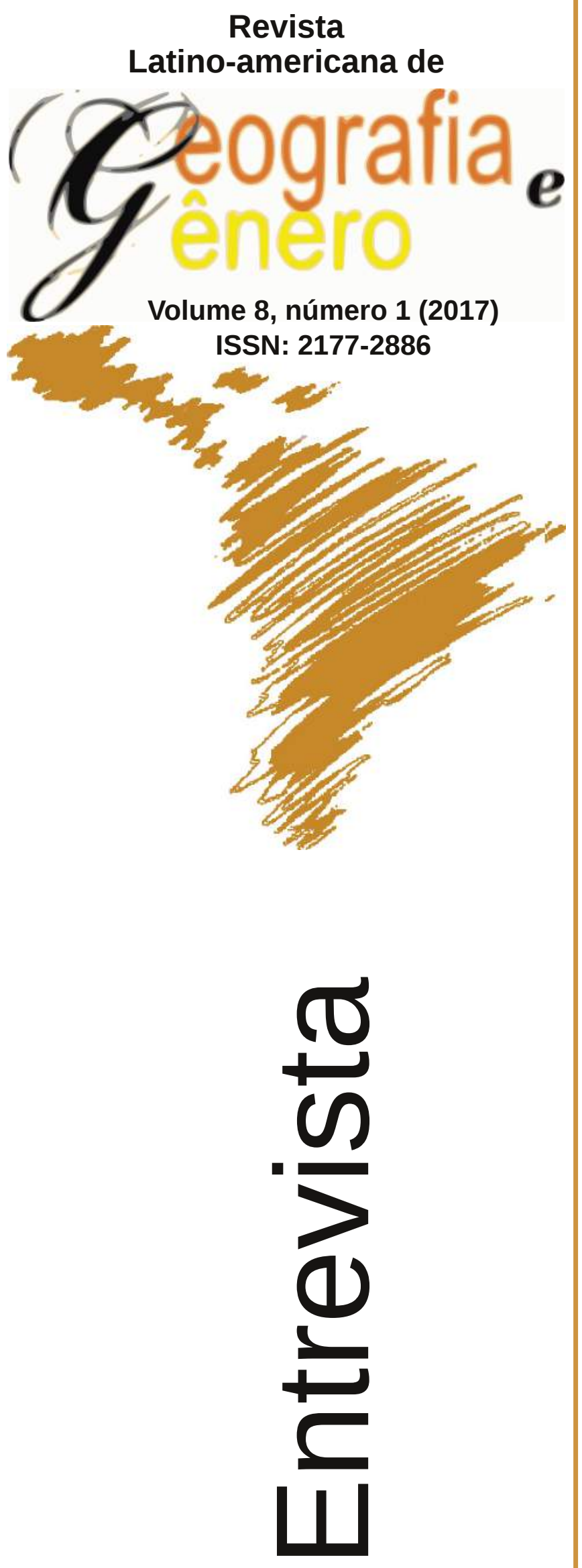

\title{
Geografias Lésbicas: Uma Entrevista com Eduarda Ferreira
}

Geografías Lesbianas: una Entrevista con Eduarda Ferreira

Lesbian Geographies: an Interview with Eduarda Ferreira

\section{Joseli Maria Silva}

Universidade Estadual de Ponta Grossa - Brasil Grupo de Estudos Territoriais joseli.genero@gmail.com

\section{Marcio Jose Ornat}

Universidade Estadual de Ponta Grossa - Brasil Grupo de Estudos Territoriais geogenero@gmail.com

Como citar:

SILVA, Joseli Maria; ORNAT, Marcio Jose. Geografias Lésbicas: uma Entrevista com Eduarda Ferreira. Revista Latino Americana de Geografia e Gênero, v. 8, n. 1, p. 424-434, 2017. ISSN 2177-2886.

Disponível em:

http://www.revistas2.uepg.br/index.php/rlagg 
Introdução

A abordagem das mulheres lésbicas tem sido marginais, tanto nas geografias feministas, como nas geografias das sexualidades. Embora ainda pouco desenvolvida, é um campo de exploração científica importante para superar as relações de poder e injustiças que marcam a vida de mulheres que escapam à heteronormatividade. Construir a visibilidade científica desse grupo é parte do projeto de Eduarda Ferreira, que tem lutado para desconstruir a homofobia que permeia a produção científica, Psicóloga e investigadora na área das geografias de gênero e sexualidades.

Recentemente Eduarda Ferreira, juntamente com Kath Browne lançaram o livro 'Lesbian Geographies. Gender, Place and Power', no qual são exploradas as vivências espaciais de mulheres lésbicas em variados contextos geográficos, diferentes escalas e questiona as hegemonias que instituem o campo de saber geográfico, bem como a força da enunciação anglófona.

Esta brilhante militante e cientista também tem importante papel na instituição e manutenção da Revista Les Online, criada em 2009 e na Rede de Estudos de Geografia, Gênero e Sexualidades Ibero-Latino Americana (REGGSILA), criada em 2014. Estes esforços são grandes contribuições para constituir um campo científico mais fraterno entre países do norte e sul global, e também questionar as relações de gênero e sexualidades que constituem o cotidiano do fazer científico.

Trazer neste volume da Revista Latino-americana de Geografia e Gênero a vivência, a luta e a produção científica de Eduarda Ferreira é uma grande felicidade para nós, sobretudo, pela admiração que nutrimos pela sua trajetória como pesquisadora na área de Geografia. Assim como nós, esperamos que esta entrevista instigue e inspire muitas mulheres, lésbicas ou não, a produzir espaço no campo científico do qual fazemos parte. É preciso lutar para conquistar, é preciso força para manter e é preciso ousadia para saber que a ciência é sim lugar para todas as mulheres.

\section{Desenvolvimento}

Joseli Maria Silva (J.M.S.) e Marcio Jose Ornat (M.J.O.): Sua trajetória como pesquisadora tem se voltado para as relações de gênero e sexualidades. Pode explorar um pouco dessa trajetória de aproximação com esses temas em sua carreira científica?

Eduarda Ferreira (E.F.): A minha trajetória como investigadora começou após um largo período de intervenção social e política em associações feministas e de defesa dos direitos das lésbicas. Foi a partir desta prática de ativismo que surgiu o meu trabalho como investigadora. Senti a falta de investigação em Portugal sobre os temas que trabalhava na intervenção social e política, senti a falta de suporte teórico para melhor refletir a intervenção ativista. Estando direcionada para as questões específicas relacionadas com as mulheres lésbicas, desde sempre a minha investigação cruzou as questões de gênero com sexualidades. As fronteiras entre a academia e o ativismo são difusas, existem sobreposições entre o que é ser ativista e o ser acadêmica, 
entre as práticas de investigação e as ações políticas (SILVA; FERREIRA, 2011). O ativismo não é uma prática isolada em determinados momentos e espaços, é um processo que se desenvolve em diversos contextos do percurso de vida. A atividade acadêmica de alguém que adota uma postura ativista será necessariamente também uma área de intervenção social e política (RUDDICK, 2004). E é desta forma que entendo a minha atividade acadêmica e ativismo, como interligados e interdependentes.

\section{J.M.S. e M.J.O.: Sua trajetória profissional também evidencia uma atuação no campo da educação. Como sua atuação com gênero e sexualidades está interseccionada com a educação?}

E.F.: A minha atividade profissional é como psicóloga educacional. Trabalho com crianças e jovens no âmbito do apoio psicopedagógico e de orientação escolar e profissional. As questões relacionadas com gênero e sexualidades são fundamentais no contexto educativo. Trabalhamos com jovens que se questionam, que procuram entender-se a si e ao mundo que os rodeia. A adolescência é uma época da vida muito intensa em que muitas questões se levantam, nomeadamente relacionadas com a sexualidade. Durante os anos de juventude as questões identitárias assumem particular relevo, e o espaço escolar é um ambiente privilegiado das interações dos jovens. Da minha experiência, verifico que em Portugal não existe uma abordagem inclusiva em contexto escolar das questões relacionadas com orientação sexual e identidade de gênero. E esta é uma lacuna importante que urge ultrapassar. A educação é uma das áreas prioritárias de intervenção para a promoção de uma sociedade mais inclusiva e respeitadora da diversidade. Em Portugal, temos alguns exemplos de legislação que suporta e promove estes princípios. A Lei da Educação Sexual em Meio Escolar (Lei n. ${ }^{\circ}$ 60/2009 de 6 de agosto), apresenta como duas das finalidades da educação sexual: “f) $\mathrm{O}$ respeito pela diferença entre as pessoas e pelas diferentes orientações sexuais; (...) 1) A eliminação de comportamentos baseados na discriminação sexual ou na violência em função do sexo ou orientação sexual". No entanto, da lei à prática a distância é grande e existem poucos projetos desenvolvidos no espaço escolar em que a área de intervenção prioritária esteja relacionada com a orientação sexual. Na minha atividade enquanto investigadora/ativista, colaboro com diversas associações que desenvolvem projetos de intervenção em contexto escolar sobre orientação sexual e identidade de gênero. O projeto mais recente em que estou envolvida articula a atividade das bibliotecas escolares com a dinamização de atividades de reflexão sobre questões relacionadas com gênero e sexualidades. O projeto chama-se 'Livros Viajantes Inclusivos' www.livrosviajantesinclusivos.info e tem como desafio inicial a necessidade de colocar a escola no centro da promoção da educação para a Igualdade. Este projeto tem como objetivo a dinamização em contexto escolar de atividades sobre não discriminação em função da orientação sexual e identidade de gênero no contexto das atividades desenvolvidas pelas bibliotecas escolares. São distribuídos às bibliotecas escolares livros que abordam questões relacionadas com a orientação sexual e/ou identidade de gênero, que incluem referências não estereotipadas nem preconceituosas a 
personagens com orientação sexual não-heterossexual ou transgênero, e também livros cujos/as autores/as assumem/iram uma postura de visibilidade relativamente à sua orientação sexual não-heterossexual. Um dos aspetos mais interessantes deste projeto é a realização de atividades sobre orientação sexual e identidade de gênero com crianças do $1^{\circ}$ ciclo.

\section{J.M.S. e M.J.O.: Como avalia a abordagem de gênero e sexualidades na geografia de Portugal, considerando sua vivência como pesquisadora lésbica e feminista?}

E.F.: A investigação em Portugal sobre as geografias de gênero e sexualidades é incipiente. Não existem ofertas de formação graduada ou pósgraduada que aborde estas temáticas. Existe algum trabalho na área das geografias de gênero mas a interseção com as sexualidades é quase inexistente (FERREIRA; SILVA, 2011). Por exemplo, para a realização da minha tese de doutoramento foi necessário recorrer a uma orientadora fora de Portugal, Gill Valentine, por não existir ninguém em Portugal já doutorado que trabalhasse na área da Geografia as interseções entre gênero e sexualidades. Fora da Geografia, encontramos alguma investigação na área do gênero e sexualidades, nomeadamente na Sociologia. Mas, para além de ser um número muito reduzido de investigadoras/es que trabalham estas questões, quase todas/os têm uma participação ativista muito relevante em associações de direitos LGBTI (FERREIRA; SILVA, 2011). Esta constatação faz ressaltar a importância da posicionalidade do/a investigador/a e de como a investigação é influenciada pelo enquadramento pessoal, social, econômico e cultural das/os investigadoras/es. Por outro lado não deixa de ser merecedor de reflexão o fato de não existirem investigadores/as fora da área dos ativismos a estudar estas questões. A LES Online, publicação digital sobre questões lésbicas, surgiu exatamente dessa necessidade de dar visibilidade à investigação relacionada com gênero e sexualidade e teve como objetivo dinamizar esta área de investigação.

J.M.S. e M.J.O.: Em sua tese de doutorado, "Reconceptualising public spaces of (in)equality: Sensing and Creating Layers of Visibility", há uma crítica em torno da ideia moderna de espaço público. Como avalia a relação entre espaço público, gênero e sexualidades?

E.F.: O espaço é uma parte essencial da constituição e reprodução das identidades sociais, e as identidades sociais, os seus significados e relações produzem espaços materiais, simbólicos e metafóricos. Com base nesta relação mútua podemos entender como o espaço reflete as relações de poder e os discursos hegemônicos, e como as desigualdades podem perpetuar-se através das formas pelas quais o espaço é organizado, vivenciado, representado e criado (MASSEY, 2005). Em particular as identidades sexuais têm uma forte componente espacial. A possibilidade de invisibilidade da orientação sexual realça a importância do espaço na cidadania sexual. É possível não revelar a orientação sexual, e num contexto de discriminação social a invisibilidade é uma opção comum (FERREIRA, 2011; VALENTINE, 1996). Aspetos 
específicos das identidades são visíveis ou destacam-se em determinados espaços e momentos, estando este processo relacionado com as relações de poder inscritas nas formas como os espaços são organizados e vivenciados (VALENTINE, 2007). A análise das interseções entre cidadania sexual e espaço permite identificar a importância das questões de gênero nas identidades sexuais. O sexo continua a ser um eixo saliente de diferença, e a heteronormatividade ou a homonormatividade não afetam as lésbicas e os gays da mesma forma. A interpretação dos espaços públicos exclusivamente em função de um binário heterossexual / homossexual não é adequada no caso das lésbicas, tendo em conta as assimetrias de gênero existentes. As diferenças na presença espacial de gays e lésbicas no espaço público são muitas vezes abordadas na investigação acadêmica, no entanto, a perceção das lésbicas como 'invisíveis' na paisagem urbana é muitas vezes um produto de modelos conceituais que dependem de visibilidade na paisagem material (PODMORE, 2001). Uma abordagem às espacialidades baseada nos aspetos materiais do território poderá não identificar espaços significativos na vida das lésbicas (BINNIE; VALENTINE, 1999). Por exemplo, alguns estudos sobre espaços comerciais LGBT não identificam espaços lésbicos, tais como bares de lésbicas, principalmente porque eles não estão localizados nos territórios em estudo. Para revelar os padrões espaciais das sociabilidades lésbicas a investigação tem de incorporar abordagens mais complexas e desterritorializadas (PODMORE, 2001). O trabalho realizado por Valentine (1996) é um exemplo da utilização de abordagens desterritorializadas que permitem identificar as espacialidades urbanas das lésbicas através de aspetos intangíveis como a forma de vestir, a linguagem, a música e muitas outras formas, como fazer compras em casal ou socialização em grupos. As relações entre a produção de espaço e a produção sistemática de poder revelam a forma como a intersecionalidade é espacialmente constituída e experienciada. Num contexto de heteronormatividade nos espaços públicos, em que as/os heterossexuais cisgênero não se sentem constrangidas/os na expressão pública da sua identidade sexual, as lésbicas estão permanentemente conscientes de que os seus comportamentos podem tornar visível a sua orientação sexual, levando a uma constante autovigilância e a uma noção interiorizada da relação mútua de constituição e reprodução entre identidades e espaços (VALENTINE, 1996). Esta constante autovigilância das lésbicas nos espaços públicos pode levar a sentimentos de distanciamento, desconforto e não pertença, com efeitos negativos na sua qualidade de vida. A invisibilidade das lésbicas é simultaneamente uma causa e uma consequência das desigualdades nas suas vidas diárias (FRA, 2009). É importante salientar que, mesmo nos países com legislação que defende a não-discriminação em função da orientação sexual, as demonstrações de afeto entre pessoas do mesmo sexo não são aceites ou respeitadas nos espaços públicos, o que comprova a existência generalizada de um contexto de heteronormatividade (FERREIRA, 2011). Uma das formas de discriminação social mais comum é a forte pressão da sociedade para confinar e esconder as sexualidades lésbicas dentro de espaços privados (VALENTINE, 1993). A visibilidade lésbica é muitas vezes conseguida de uma forma codificada, reconhecível apenas por aquelas que partilham a mesma subcultura, reafirmando um sentido de pertença e de resistência à hegemonia 
de um espaço público heterossexista. A noção de 'comunidades imaginadas' em que as pessoas se identificam como membros mesmo sem nunca chegarem a conhecer os outros membros, desenvolvendo uma imagem mental de grupo ou comunidade é utilizado por Rothenberg (1995) para explicar a forma como as lésbicas constroem um sentimento de comunidade e de pertença. A perceção de 'outras como nós' tem um impacto significativo na forma como as lésbicas percecionam o espaço, promovendo um sentimento de segurança nos espaços públicos. A minha investigação de doutoramento apresenta resultados que permitem afirmar que criar e partilhar camadas digitais de visibilidade lésbica em mapas colaborativos online pode contribuir para aumentar a perceção de segurança, o sentimento de pertença, e a probabilidade de expressões públicas de afeto entre mulheres, criando paisagens de espaços públicos menos discriminatórios e mais inclusivos para lésbicas e mulheres bissexuais (FERREIRA; SALVADOR, 2015). Como aplicação prática dos resultados da investigação que realizei, lancei o projeto LES friendly http://lesfriendly.pt/ que tem por objetivo criar e partilhar um mapa colaborativo em ambiente online com informação sobre espaços públicos friendly para mulheres num relacionamento afetivo/sexual com outras mulheres nas cidades de Lisboa e Porto.

J.M.S. e M.J.O.: Em seu capítulo de livro, 'Questões de gênero e orientação sexual em espaço escolar', há a utilização da internet como uma importante ferramenta de expressão para jovens. Como considera a interseção entre novas tecnologias e acolhimento dos desejos e enunciação de jovens LGBT?

E.F.: A definição/construção dos aspetos da identidade relacionados com a orientação sexual é um processo difícil, doloroso e inacabado (THOMPSON; MORGAN, 2008) e os anos de juventude são determinantes no desenvolvimento do processo identitário. A pressão do meio envolvente no sentido da invisibilidade de um dos aspetos fundamentais no desenvolvimento sócio emocional, a esfera afetiva e sexual, pode ter efeitos prejudiciais significativos e duradouros (RUSSELL, 2011). A grande maioria dos jovens LGBT vive em contextos familiares, escolares e sociais heteronormativos, em que é esperado que eles/as sejam heterossexuais. Nestes contextos a socialização da sua orientação sexual é limitada. Esta realidade não promove a aprendizagem de estratégias para lidar com a discriminação social que enfrentam, nem facilita a consciencialização de que a exclusão social não está relacionada com as suas características individuais, mas sim com o contexto heteronormativo em que vivem (RUSSELL, 2011). Num contexto de discriminação social em que o discurso hegemônico da heteronormatividade está literalmente inscrito no espaço público, incluindo o espaço escolar, o espaço virtual é muitas vezes utilizado como forma de expressão da orientação sexual (BUCKINGHAM; WILLETT 2006). É importante reconhecer como a omnipresença da tecnologia e das formas digitais de comunicação nas vidas das/os jovens tornou a comunicação digital tão frequente e natural como a comunicação face-a-face (GREEN; HANNON, 2007; FERREIRA; TOMÉ, 2010). Neste novo contexto de comunicação digital dominante, com a possibilidade de anonimato e o acesso facilitado a realidades distantes 
geograficamente, as novas tecnologias vieram trazer um novo espaço de construções identitárias. No caso dos jovens LGBTI as novas tecnologias, e a Internet em particular, permitem novas formas de exploração e de estabelecimento de redes de apoio, fundamentais para lidar com os contextos sociais ainda tão carregados de discriminação.

J.M.S. e M.J.O.: O livro 'Lesbian Geographies. Gender, Place and Power' (BROWNE; FERREIRA, 2015) traz em sua totalidade mulheres, embora não esteja explícita a orientação sexual, creio que a maioria delas são lésbicas. Essa escolha foi pautada no projeto do livro, ou é uma coincidência do universo de pesquisadoras sobre a temática? Como avalia relação entre pesquisa, realidade da pessoa pesquisadora e luta política?

E.F.: A orientação sexual das autoras que contribuíram para o livro 'Lesbian Geographies. Gender, Place and Power' (BROWNE; FERREIRA, 2015) nunca foi questionada ou mencionada. São de fato todas mulheres e todas investigadoras de questões relacionadas com gênero e sexualidades. Creio que pelas afirmações e posicionalidades das autoras muitas se auto identificam como lésbicas, o que traduz uma realidade ao nível da academia de diversos países, em que determinados temas de investigação só são abordados por pessoas diretamente envolvidas nas realidades estudadas. As interseções entre poder, conhecimento e subjetividade foram evidenciadas pelas teorias feministas, ao tornarem manifestas as relações entre o posicionamento social, valores e atitudes das/os investigadoras/es e a forma como o pensamento científico é construído (MASSEY, 1994; SILVA, 2010). As questões investigadas, as metodologias utilizadas e as formas de divulgação dos resultados, são alguns exemplos de aspetos da investigação que são influenciados pelo enquadramento pessoal, social, econômico e cultural das/os investigadoras/es. Como Doreen Massey (2000) argumenta, a investigação acadêmica deve ultrapassar a mera produção de artigos, livros e relatórios que se acrescentam ao curriculum; as/os investigadoras/es devem ter a noção de que estão a lançar algo num fluxo, numa proliferação de conexões, que produz efeitos na realidade sobre que se debruça e é simultaneamente influenciado por essa mesma realidade. E é nesse espírito que as autoras deste livro se uniram para produzir algo que possa não só contribuir para o avanço do conhecimento científico, mas também ter um impacto concreto na vida de todas/os nós. $\mathrm{O}$ desenvolvimento da investigação com exercício de advocacia, nomeadamente da identitária contribui para a criação de espaços mais inclusivos, visibilizando a diversidade e retirando espaços à discriminação.

J.M.S. e M.J.O.: A Rede de Estudos de Geografia, Gênero e Sexualidades Ibero-Latino Americana foi criada entre países europeus que colonizaram a América Latina. Como avalia esta relação de poder e a possibilidade de criar uma produção acadêmica menos hierarquizada, notadamente frente ao mundo anglófono?

E.F.: O que une as/os investigadoras/es da REGGSILA é uma atitude de investigação situada que é simultaneamente de intervenção social e política, 
baseada num enquadramento teórico feminista assente na posicionalidade e na consciência da centralidade do corpo nas questões de gênero e na sexualidade, na consciência das relações de poder e no assumir que a produção de conhecimento é simultaneamente pessoal e política. Para além deste posicionamento comum, o contexto geográfico, histórico e cultural e o fato de utilizarmos a língua espanhola e a língua portuguesa, é uma base de trabalho para rompermos com a hegemonia anglófona nas geografias de gênero e sexualidades. A prevalência anglófona não se limita só à utilização do inglês como língua de trabalho, mas a uma hegemonia cultural e de formas de produção de conhecimento. Existe mais conhecimento para além do produzido nos países anglófonos e essencialmente existem outras realidades para além das que são estudadas por investigadores/as que provêm de um contexto cultural anglófono. Mesmo quando investigadoras/es anglófonos investigam realidades fora dos seus países interpretam essas realidades a partir do seu posicionamento cultural. Questionamos esta hegemonia cultural anglosaxônica e a hierarquização das formas de produção de conhecimento. A existência de redes como a REGGSILA contribui para dar sustentabilidade e visibilidade à investigação em contextos Ibéricos e Latino Americanos (ILA) promovendo diversidade de discursos numa área do conhecimento que se tem caracterizado por um discurso hegemônico. A divulgação e visibilidade da investigação em geografias de gênero e sexualidades em contextos ILA constitui um importante contributo para as ciências sociais em geral e para a geografia social e cultural em particular.

\section{J.M.S. e M.J.O.: Por fim, gostaria que explorasse a sua atuação como editora da Revista Les Online, os limites e potencialidades de luta social e científica para mulheres lésbicas.}

E.F.: Em Portugal, existe um défice na investigação científica na área dos direitos sexuais e reprodutivos, e em particular na área das questões relacionadas com a temática lésbica. Já existem algumas investigações de mestrado e doutoramento relacionadas com a temática da orientação sexual, mas a sua divulgação também é deficitária. Um dos objetivos da LES Online é contribuir para divulgar o trabalho de investigação que já existe, e acreditamos que a existência de um espaço de divulgação dos trabalhos realizados, permitindo a reflexão sobre esta temática, pode contribuir para a promoção de mais estudos nesta área. No início de 2008, em conjunto com um grupo de mulheres, iniciei um novo projeto: LES - Grupo de Discussão sobre Questões Lésbicas. Este projeto surgiu da necessidade de criar um espaço de reflexão, dando continuidade ao trabalho iniciado no Blog "Sexualidades no Feminino" (http://sexualidadesnofeminino.blogspot.com/) realizado em parceria com Maria João Silva. No texto de apresentação do LES em www.lespt.org, podemos ler:

“O LES - Grupo de Discussão sobre Questões Lésbicas pretende contribuir para a reflexão sobre as questões lésbicas e para o desenvolvimento de ações que promovam os direitos e a igualdade de oportunidade das mulheres lésbicas nas várias dimensões da sua vida. Queremos, desta forma, colaborar na criação de uma melhor qualidade de vida para todas e todos. Desejamos que o LES se 
caracterize pela diversidade de temas, de formas de abordagem e de colaborações. Procuraremos, neste contexto, divulgar e publicar opiniões, discussões temáticas, pesquisas e investigações sobre Questões Lésbicas não só na Internet, mas também em encontros, conferências e congressos." Para além da realização de encontros temáticos, este grupo iniciou um projeto inovador em Portugal, a LES Online - publicação digital sobre questões lésbicas (http://www.lespt.org/lesonline). A LES Online é uma publicação digital que tem como objetivo divulgar estudos e investigações de caráter científico, assim como projetos de intervenção e artigos de opinião, relacionados com as diversas vertentes da temática lésbica. Para além da Equipe Editorial, a revista inclui uma Comissão Consultiva de modo a assegurar a qualidade da revisão dos artigos submetidos. A equipa responsável pela LES Online, ao tentar contextualizar o seu trabalho de intervenção na área da defesa dos direitos das lésbicas, deparou-se com a dificuldade em encontrar abordagens teóricas que tivessem em linha de conta a especificidade da realidade das lésbicas. A esmagadora maioria das abordagens das questões lésbicas está relacionada com uma análise no âmbito do feminismo ou das questões LGBT. No entanto, o nosso trabalho nesta área colocou-nos perante uma paisagem específica com dimensões que, no nosso entender, não são possíveis de estudar e de compreender tendo como base uma abordagem feminista ou uma abordagem LGBT. E foi exatamente este o ponto de partida da LES Online. Convidámos investigadores/as e ativistas para partilharem as suas visões e argumentos sobre o seguinte problema: Os temas relacionados com as lésbicas são frequentemente abordados num enquadramento feminista ou LGBT. Existem questões que não se tornam visíveis em contextos feministas ou LGBT? Há necessidade de uma abordagem específica? No dia 22 de Janeiro de 2010 foi feita a apresentação pública da publicação na Escola Superior de Educação do Porto. Durante 7 anos publicamos 10 números com um total de 71 artigos, incluindo seções de narrativas sobre a participação das mulheres no movimento LGBT, intervenção social e política e recensões de livros. Apesar de todos os esforços de divulgação, tem sido cada vez mais difícil manter a periocidade da LES Online. Compreendemos que por um lado existem poucas/os investigadores/as a trabalhar especificamente sobre questões lésbicas e por outro lado existe uma enorme pressão para publicar em revistas indexadas. Por estas razões a publicação da LES Online foi suspensa e passará a estar integrada na RLAGG como uma seção direcionada para as questões lésbicas. Esta colaboração entre a RLAGG e a LES Online é um muito bom exemplo das potencialidades da Rede de Estudos de Geografia, Gênero e Sexualidades Ibero-Latino Americana.

\section{Referências}

BINNIE, John; VALENTINE, Gill. Geographies of sexuality: a review of progress. Progress in Human Geography, v. 3, n. 2, p. 175 - 187, 1999.

BROWNE, Kath; FERREIRA, Eduarda. Lesbian Geographies. Gender, Place and Power. Farnham- England: Ashgate Publishing Limited, 2015. 
BUCKINGHAM, David, WILLETT Rebekah. Digital generations: children, young people, and new media. New Jersey: Routledge, 2006.

FERREIRA, Eduarda, SALVADOR, Regina. Lesbian collaborative web mapping: Disrupting heteronormativity in Portugal. Gender Place and Culture, v. 22, n. 7, p. 954 - 970, 2015.

FERREIRA, Eduarda, TOMÉ, Irene. Jovens, Telemóveis e Escola. Educação, Formação \& Tecnologias, n. extra, p. 24 - 34, 2010.

FERREIRA, Eduarda. Geographies of (in)equalities: space and sexual identities. In: SALVADOR, Regina; FIRMINO, Ana; PONTE, Cristina; FERREIRA, Eduarda (Orgs.). Proceedings of Geographies of Inclusion: challenges and opportunities. Lisboa: e-GEO, 2011, p. 36 - 60.

FERREIRA, Eduarda. Questões de gênero e orientação sexual em espaço escolar. In: SILVA, Joseli Maria; SILVA, Augusto Cesar Pinheiro. Espaço, gênero e poder: conectando fronteiras. Ponta Grossa: Todapalavra, 2011, p. 43 $-66$.

FERREIRA, Eduarda. Reconceptualising public spaces of (in)equality: Sensing and Creating Layers of Visibility. 2014. Tese (Geografia e Planeamento Territorial) - Universidade Nova de Lisboa, Lisboa.

FERREIRA, Eduarda; SILVA, Maria João. Equality policy in Portugal: the case of sexual orientation. In: MOTMANS, Joz; CUYPERS, Daniël; MEIER, Petra; MORTELMANS, Dimitri; ZANONI, Patrizia (Eds.) Equal is not enough: challenging differences and inequalities in contemporary societies. Antwerp: Policy Research Centre on Equal opportunities, 2011, p. $142-155$.

GREEN, Hannah, HANNON, Celia. Their Space: Education for a digital generation. London: Demos, 2007.

MASSEY, Doreen. Space, Place and Gender. Oxford: Polity Press and Blackwell, 1994.

MASSEY, Doreen. Editorial: practicing political relevance. Transactions of the Institute of British Geographers, v. 25, n. 2, p. 131 - 33, 2000.

MASSEY, Doreen. For Space. London: Sage, 2005.

PODMORE, Julien. Lesbians in the Crowd. Gender, Place and Culture, v. 8, n. 4, p. $333-355,2001$.

ROTHENBERG, Tamar. 'And She Told Two Friends': Lesbians Creating Urban Social Space. In: BELL, David; VALENTINE, Gill. Mapping Desire: Geographies of Sexualities. New York: Routledge, 1995, p. 165 - 181.

RUSSELL, Stephen. Challenging homophobia in schools: policies and 
programs for safe school climates. Educar em Revista, n. 39, p.123 - 138, 2011.

SILVA, Joseli Maria. Geografias feministas, sexualidades e corporalidades: desafios as práticas investigativas da ciência geográfica. Espaço e Cultura, n. 27, p. $39-56,2010$.

THOMPSON, Elisabeth Morgan; MORGAN, Elisabeth. 'Mostly Straight' Young Women: Variations in Sexual Behavior and Identity Development. Developmental Psychology, n. 44, v. 1, p. 15 - 21, 2008.

VALENTINE, Gill. Negotiating and managing multiple sexual identities: lesbian time-space strategies. Transactions of the Institute of British Geographers, v. 18, n. 2, p. 237 - 248, 1993.

VALENTINE, Gill. Theorizing and researching intersectionality: a challenge for feminist geography. The Professional Geographer, v. 59, n. 1, p. 10 - 21, 2007.

VALENTINE, Gill. Renegotiating the 'heterosexual street': lesbian productions of space. In: DUNCAN, Nancy (Ed.) Body Space: destabilizing geographies of gender and sexuality. London: Routledge, 1996, p. 147 155.S 